\title{
Fixed Points Theorems for Weakly Compatible Maps along with Property (E.A.)
}

\author{
S. Mudgal \\ Department of Mathematics \\ Echelon Institute of Technology \\ Jasana, Faridabad-121101, India.
}

\begin{abstract}
In this paper, we prove common fixed point theorems for a pair of weakly compatible maps under E.A .property. A major benefit of property (E.A.) is that it ensures convergence of desired sequences without completeness. At the end we rectify the main result of the paper, entitled "Common fixed points for weakly compatible maps, Proc. Indian Acad. Sci. (Math. Sci.) Vol. 111(2001), No. 2, pp 241-247.
\end{abstract}

Keywords: E.A. Property, Fixed Points Theorems, Weakly Compatible Maps

\section{INTRODUCTION}

There has been a considerable interest to study common fixed point for a pair (or family) of mappings satisfying contractive conditions in metric spaces for the last quarter of the $20^{\text {th }}$ century. Several interesting and elegant results were obtained in this direction by various authors. It was the turning point in the "fixed point arena" when the notion of commutativity was It is clear that every self mapping $\mathrm{T}$ of $\mathrm{X}$ satisfying condition (1.1) is continuous but may fail to do so if $\mathrm{T}$ satisfies condition (1.2). In late 70's many generalizations of the condition (1.1) and (1.2) appeared. Difficulty arises in obtaining common fixed points for a pair of maps. To focus such pioneer problem we shall first generalize the condition (1.1) for a pair of self maps $S$ and $T$ of $X$ in two ways:

(1.3) $\quad \mathrm{d}(\mathrm{Sx}, \mathrm{Ty}) \leq \alpha \cdot \mathrm{d}(\mathrm{x}, \mathrm{y})$ for all $\mathrm{x}, \mathrm{y} \in \mathrm{X}$, where $0 \leq \alpha$ $<1$, and

(1.4) $\mathrm{d}(\mathrm{Sx}, \mathrm{Sy}) \leq \alpha . \mathrm{d}(\mathrm{Tx}, \mathrm{Ty})$ for all $\mathrm{x}, \mathrm{y} \in \mathrm{X}$, where $0 \leq \alpha$ $<1$.

To prove the existence of common fixed points for (1.3) we shall choose an arbitrary point $\mathrm{x}_{0}$ in $\mathrm{X}$ and define a sequence $\left\{x_{n}\right\}$ of $X$ by $x_{2 n+1}=S x_{2 n}, x_{2 n+2}=T x_{2 n+1}, n \in N_{0}$. For the inequalities such as (1.4), it is necessary to add additional assumptions of the following type:

(i) construction of the sequence $\left\{\mathrm{x}_{\mathrm{n}}\right\}$ (ii) some mechanism to obtain common fixed point and this problem was over by imposing additional hypothesis of commutative pair of $\{\mathrm{S}, \mathrm{T}$ \} by Jungck [5] Most of the papers with the generalization in the lines of condition (1.4) followed a similar pattern of maps:

(i) contraction (ii) continuity of functions (either one or both) and (iii) commuting pair of mappings were given. In some cases condition (ii) can be relaxed but condition (i) and (iii) are unavoidable. The answer of the Global problem, How to develop extensively this theory? was affirmatively answered used by Jungck [6] to obtain a generalization of Banach's fixed point theorem for a pair of mappings. This theorem has had many applications, but suffers from one drawback-the definition requires that $T$ be continuous throughout $X$. This result was further generalized and extended in various ways by many authors. On the other hand, Sessa [15] coined the notion of weak commutativity and proved a common fixed point theorem for these mappings.

In particular we have to look first why we need such type of maps in the context of common fixed point theorem in metric spaces.

Start with the following contraction conditions:

Let $\mathrm{T}$ be a mapping from a complete metric space $(X, d)$ into itself and consider the following conditions:

(1.1) $\mathrm{d}(\mathrm{Tx}, \mathrm{Ty}) \leq \alpha . \mathrm{d}(\mathrm{x}, \mathrm{y})$ for all $\mathrm{x}, \mathrm{y} \in \mathrm{X}$, where $0 \leq \alpha<1$,

(1.2) $d(T x, T y) \leq \beta \cdot[d(x, T x)+d(y, T y)]$ for all $x, y \in X$, where $0 \leq \beta<1 / 2$.

when mathematicians diverted their research in the direction of conditions (i) and (iii).

Now we give preliminaries and basic definitions which are used throughout the paper.

Definition 1.1. Two self-mappings $f$ and $g$ be of a metric space $(X, d)$ are said to be weakly commuting if $d(f g x, g f x)$ $\leq \mathrm{d}(\mathrm{gx}, \mathrm{fx})$ for all $\mathrm{x}$ in $\mathrm{X}$.

In last two decades, a major breakthrough was done when Jungck 6] introduced the notion of "compatibility of mapping". This concept has been very useful for obtaining fixed point theorems for pairs of mappings satisfying a contractive type conditions and assuming continuity of at least one of mappings.

Definition 1.2.[6] Two self-mappings $f$ and $g$ of a metric space $(X, d)$ are said to be compatible if $\lim _{n \rightarrow \infty} d\left(f g x_{n}, g f x_{n}\right)=$ 0 , whenever $\left\{x_{n}\right\} \infty_{n=1}$ is a sequence in $X$ such that $\lim _{n \rightarrow \infty}$ $\mathrm{fx}_{\mathrm{n}}=\lim _{n \rightarrow \infty} \mathrm{gx}_{\mathrm{n}}=\mathrm{t}$ for some $\mathrm{t}$ in $\mathrm{X}$.

The study of common fixed points theorems for non compatible mappings is also interesting and first initiated by Pant [12] with the introduction of the notion of R-weakly commuting mappings in metric spaces. 
Definition 1.3. A pair of self-mappings (f, $g$ ) of a metric space $(\mathrm{X}, \mathrm{d})$ is said to be R-weakly commuting if there exists some $\mathrm{R}>0$ such that

$\mathrm{d}(\mathrm{fgx}, \mathrm{gfx}) \leq \mathrm{Rd}(\mathrm{fx}, \mathrm{gx}$,$) for all \mathrm{x} \in \mathrm{X}$ and $\mathrm{t}>0$.

In 1997, Pathak Cho and Kang [11] improved the notion of Rweakly commuting mappings to the notion of R-weakly commuting mappings of type $\left(\mathrm{A}_{\mathrm{g}}\right)$ and R-weakly commuting mappings of type $\left(\mathrm{A}_{\mathrm{f}}\right)$.

Definition 1.4. A pair of self-mappings ( $f, g$ ) of a metric space $(\mathrm{X}, \mathrm{d})$ is said to be

(i) R-weakly commuting mappings of type ( $\mathrm{Ag}$ ) if there exists some $\mathrm{R}>0$ such that

$$
\mathrm{d}(\mathrm{gfx}, \mathrm{ffx}) \leq \operatorname{Rd}(\mathrm{fx}, \mathrm{gx}) \text { for all } \mathrm{x} \in \mathrm{X} .
$$

(ii) R-weakly commuting mappings of type $\left(\mathrm{A}_{\mathrm{f}}\right)$ if there exists some $\mathrm{R}>0$ such that

$\mathrm{d}(\mathrm{fgx}, \operatorname{ggx}) \leq \mathrm{R} \mathrm{d}(\mathrm{fx}, \mathrm{gx})$ for all $\mathrm{x} \in \mathrm{X}$.

In 1998, Jungck and Rhoades [7] introduced the notion of weakly compatible as follow:

Definition 1.5. Two maps $f$ and $g$ are said to be weakly compatible if they commute at coincidence points.

Example 1.1. Weakly compatible maps need not be compatible.

Let $X=[2,20]$ and $d$ be the usual metric on $X$. Define mappings

$\mathrm{B}, \mathrm{T}: \mathrm{X} \rightarrow \mathrm{X}$ by $\mathrm{Bx}=\mathrm{x}$ if $\mathrm{x}=2$ or $>5, \mathrm{Bx}=6$ if $2<\mathrm{x} \leq 5$, $\mathrm{Tx}=\mathrm{x} \quad$ if $\mathrm{x}=2, \mathrm{Tx}=12$ if $2<\mathrm{x} \leq 5, \mathrm{Tx}=\mathrm{x}-3$ if $\mathrm{x}>5$. The mappings $\mathrm{B}$ and $\mathrm{T}$ are non-compatible since sequence $\left\{x_{n}\right\}$ defined by $x_{n}=(5+(1 / n), n \geq 1)$. Then $\operatorname{Tx}_{n} \rightarrow 2, B_{n}$ $\rightarrow 2, \mathrm{TBx}_{\mathrm{n}}=2$ and $\mathrm{BTx}_{\mathrm{n}}=6$. But they are weakly compatible since they commute at coincidence point at $\mathrm{x}=2$.

Now in a similar mode we can state R-weakly commuting mappings of type $(\mathrm{P})$, which seem to be unreported in the metric fixed point theory literature.

Definition 1.6. A pair of self-mappings ( $f, g$ ) of a metric space $(\mathrm{X}, \mathrm{d})$ is said to be R-weakly commuting mappings of type (P) if there exists some $\mathrm{R}>0$ such that

$\mathrm{d}(\mathrm{ffx}, \operatorname{ggx}) \leq \mathrm{Rd}(\mathrm{fx}, \mathrm{gx})$ for all $\mathrm{x} \in \mathrm{X}$.

Remark 1.1. We have some suitable examples to show that R- weakly commuting mappings, R-weakly commuting of type $\left(\mathrm{A}_{\mathrm{g}}\right)$, R-weakly commuting of type $\left(\mathrm{A}_{\mathrm{f}}\right)$ and $\mathrm{R}$-weakly commuting of type $(\mathrm{P})$ are distinct.

Example 1.2. Let $X=[-1,1]$ the set of all real numbers with usual metric $\mathrm{d}$ defined by

$$
\mathrm{d}(\mathrm{x}, \mathrm{y})=\mid x-y \quad \text { for all } \mathrm{x}, \mathrm{y} \text { in } \mathrm{X} .
$$

Define $f x=|x|$ and $g x=|x|-1$. Then by a straightforward calculation, one can show that

$\mathrm{d}(\mathrm{fx}, \mathrm{gx})=1, \mathrm{~d}(\mathrm{fgx}, \mathrm{gf} \mathrm{x})=2(1-|\mathrm{x}|), \mathrm{d}(\mathrm{fgx}, \mathrm{ggx})=1 \mathrm{~d}(\mathrm{gfx}$, $\mathrm{ffx})=1, \mathrm{~d}(\mathrm{ffx}, \mathrm{ggx})=2|x|$ for all $\mathrm{x}$ in $\mathrm{X}$.

Now we conclude the following:

(i) pair (f, g) is not weakly commuting (ii)

for $\mathrm{R}=2$, pair (f, g) is R-weakly commuting , R-weakly commuting of type $(\mathrm{P})$, Rweakly commuting of type $\left(\mathrm{A}_{\mathrm{g}}\right)$ and $\mathrm{R}$ weakly commuting of type $\left(A_{f}\right)$, for $\mathrm{R}=\frac{3}{2}$, pair (f, $\mathrm{g}$ ) is R-weakly commuting of type $\left(\mathrm{A}_{\mathrm{f}}\right)$ but not R-weakly commuting of type (P) and R-weakly commuting.

Example 1.3. Let $X=[0,1]$ the set of all real numbers with usual metric $\mathrm{d}$ defined by

$$
\mathrm{d}(\mathrm{x}, \mathrm{y})=|\mathrm{x}-\mathrm{y}| \text { for all } \mathrm{x}, \mathrm{y} \text { in } \mathrm{X} .
$$

Define $\mathrm{fx}=\mathrm{x}$ and $\mathrm{gx}=\mathrm{x}^{2}$. Then by a straightforward calculation, one can show that $f f x=x, g f x=x^{2}, f g x=x^{2}, g g x=x^{4}$ and $\mathrm{d}(\mathrm{fgx}, \mathrm{gfx})=0 \mathrm{~d}(\mathrm{fgx}, \operatorname{ggx})=\left|\mathrm{x}^{2}(x-1)(x+1)\right|$, $\mathrm{d}(\mathrm{gfx}, \quad \mathrm{ffx})=|x(x-1)|, \quad \mathrm{d}(\mathrm{ff} \mathrm{x}, \quad \mathrm{ggx}) \quad=$ $\left|x(x-1)\left(x^{2}+x+1\right)\right|$ and $\mathrm{d}(\mathrm{fx}, \mathrm{gx})=|\mathrm{x}(\mathrm{x}-1)|$ for all $\mathrm{x}$ in $\mathrm{X}$. Therefore, we conclude that

i) pair (f, g) is R- weakly commuting for all positive, real values of $R$,

ii) for $\mathrm{R}=3$, pair (f, $g$ ) is $\mathrm{R}$-weakly commuting of the type $\left(\mathrm{A}_{\mathrm{f}}\right)$, R-weakly commuting of the type $\left(\mathrm{A}_{\mathrm{g}}\right)$ and R-weakly commuting of the type $(\mathrm{P})$,

iii) for $\mathrm{R}=2$, pair ( $\mathrm{f}, \mathrm{g}$ ) is $\mathrm{R}$-weakly commuting of type $\left(\mathrm{A}_{\mathrm{f}}\right)$, and R-weakly commuting of type $\left(\mathrm{A}_{\mathrm{g}}\right)$ but not Rweakly commuting of type $(\mathrm{P})\left(\right.$ for this take $\left.\mathrm{x}=\frac{3}{4}\right)$.

Example 1.4. Consider $X=\left[\frac{1}{2}, 2\right]$. Let us define self maps f and $\mathrm{g}$ by $\mathrm{f} x=\frac{x+1}{3}, \mathrm{gx}=\frac{x+2}{5}$. We calculate the following:

$\mathrm{d}(\mathrm{fx}, \mathrm{gx})=\frac{2 x-1}{15}, \mathrm{~d}(\mathrm{fg} \mathrm{x}, \mathrm{gfx})=0, \mathrm{~d}(\mathrm{fgx}, \mathrm{ggx})=\frac{2 x-1}{75}$, $\mathrm{d}(\mathrm{gfx}, \mathrm{ffx})=\frac{2 x-1}{45}$ and $\mathrm{d}(\mathrm{ff} \mathrm{x}, \mathrm{ggx})=\frac{8}{225}(2 x-1)$ for all $\mathrm{x}$ in $\mathrm{X}$.

Now we conclude the following:

The pair $(\mathrm{f}, \mathrm{g})$ is $\mathrm{R}$-weakly commuting for all positive real numbers.

for $R \geq \frac{8}{15}$, it is R-weakly commuting of type $\left(\mathrm{A}_{\mathrm{f}}\right), \mathrm{R}$ weakly commuting of type $\left(\mathrm{A}_{\mathrm{g}}\right)$ and R-weakly commuting of type $(\mathrm{P})$.

i) for $\frac{1}{3} \leq R<\frac{8}{15}$, it is R-weakly commuting of type $\left(\mathrm{A}_{\mathrm{g}}\right)$ and R-weakly commuting of 
type $\left(\mathrm{A}_{\mathrm{f}}\right)$ but not R-weakly commuting of type $(\mathrm{P})$.

ii)

for $\frac{1}{5} \leq R<\frac{1}{3}$, it is R-weakly commuting of

type $\left(\mathrm{A}_{\mathrm{f}}\right)$ but not R-weakly commuting of type $\left(\mathrm{A}_{\mathrm{g}}\right)$ and $\mathrm{R}$-weakly commuting of type $(\mathrm{P})$.

Moreover, such mappings commute at their coincidence points. It is also obvious that $\mathrm{f}$ and $\mathrm{g}$ can fail to be point wise R-weakly commuting only if there exists some $\mathrm{x}$ in $\mathrm{X}$ such that $\mathrm{fx}=\mathrm{gx}$ but $\mathrm{fgx} \neq \mathrm{gfx}$, that is ,only if they possess a coincidence point at which they do not commute.

the notion of point wise R-weak commutativity is equivalent to commutativity at coincidence points.

In 1998, Jungck [8] introduced the notion of weakly compatible as follow:

Let $\mathrm{A}$ and $\mathrm{S}$ be self-mappings of a metric space $(\mathrm{X}, \mathrm{d})$ and $\mathrm{C}(\mathrm{A}, \mathrm{S})$ the set of coincidence points of $\mathrm{A}$ and $\mathrm{S}$.

Definition 1.7. A and $S$ are said to be weakly compatible if $\mathrm{SAu}=\mathrm{ASu}$ for all $\mathrm{u} \in \mathrm{C}(\mathrm{A}, \mathrm{S})$.

Example 1.5. Let $X=[2,20]$ and define mappings $S, T: X$ $\rightarrow \mathrm{X}$ by

$$
\begin{array}{r}
S(x)=\left\{\begin{array}{lr}
x, & \text { if } x=\{2,5\} \\
6, & \text { if } 2<x \leq 5
\end{array}\right. \\
T(x)=\left\{\begin{array}{lr}
x & \text { if } x=2 \\
12, & \text { if } 2<x \leq 5 \\
x-3, & \text { if } x>5
\end{array}\right.
\end{array}
$$

Now consider a sequence $\left\{\mathrm{x}_{\mathrm{n}}\right\}$ defined by $\mathrm{x}_{\mathrm{n}}=\left(5+\frac{1}{n}, \mathrm{n} \geq\right.$ 1). Then $\mathrm{Tx}_{\mathrm{n}} \rightarrow 2, \mathrm{Sx}_{\mathrm{n}} \rightarrow 2, \mathrm{TSx}_{\mathrm{n}} \rightarrow 2$ and $\mathrm{STx}_{\mathrm{n}} \rightarrow 6$. The mappings $\mathrm{S}$ and $\mathrm{T}$ are non-compatible, however, the maps $\mathrm{S}$ and $\mathrm{T}$ are weakly compatible since they commute at coincidence point at $\mathrm{x}=2$.

Now, there arises a natural question: "How fixed point theorems can be improved to the setting of noncomplete metric spaces and without continuity of $f$ and $g$ over the whole space $\mathrm{X}$ ?" We give the partial answer. It seems that fixed point theorems can be improved by using E.A. property.

Aamri and El Moutawakil [1] generalized the concept of non compatiblity in metric spaces by defining the notion property (E.A.) and proved common fixed point theorems under strict contractive conditions. A major benefit of property (E.A.) is that it ensures convergence of desired sequences without completeness.

Recently, Amari and Moutawakil [1] introduced a generalization of non compatible maps as property ( E. A. ) as follows: .

Definition 1.8. LetA and $S$ be two self-maps of a metric space $(X, d)$.The pair $(A, S)$ is said to satisfy property ( E. A. ) , if there exists a sequence $\left\{x_{n}\right\}$ in $X$ such that $\lim _{n \rightarrow \infty} A_{n}$ $=\lim _{\mathrm{n} \rightarrow \infty} \mathrm{Sx}_{\mathrm{n}}=\mathrm{t}$ for some $\mathrm{t}$ in $\mathrm{X}$.

Example 1.6. Let $X=[0,+\infty)$. Define $S, T: X \rightarrow X$ by $\mathrm{fx}=\frac{x}{4}$ and $\mathrm{gx}=\frac{3 x}{4}$, for all $\mathrm{x}$ in $\mathrm{X}$. Consider the sequence

$\mathrm{x}_{\mathrm{n}}=\frac{1}{n}$. Clearly $\lim _{n \rightarrow \infty} \mathrm{d}\left(\mathrm{fx}_{\mathrm{n}}, \mathrm{gx}_{\mathrm{n}}\right)=0$, then $\mathrm{f}$ and $\mathrm{g}$ satisfy property (E. A. ) .

Example 1.7. Let $X=[2,+\infty)$. Define $f, g: X \rightarrow X$ by

$\mathrm{gx}=x+1$ and $\mathrm{fx}=2 x+1$, for all $\mathrm{x} \in \mathrm{X}$. Suppose that the property (E. A. ) holds. Then, there exists a sequence $\left\{x_{n}\right\}$ in $\mathrm{X}$ satisfying $\lim _{n \rightarrow \infty} \mathrm{fx}_{\mathrm{n}}=\lim _{n \rightarrow \infty} \mathrm{gx}_{\mathrm{n}}=\mathrm{z}$ for some $\mathrm{z} \in \mathrm{X}$. Therefore, $\lim _{n \rightarrow \infty} x_{n}=z-1$ and $\lim _{n \rightarrow \infty} x_{n}=\frac{z-1}{2}$. Thus, $z=1$, which is a contradiction, since 1 is not contained in $\mathrm{X}$. Hence $\mathrm{f}$ and $\mathrm{g}$ do not satisfy E.A property.

Example 1.8. Let $X=\left[\frac{2}{3},+\infty\right)$. Define $f, g: X \rightarrow X$ by

$\mathrm{gx}=\frac{x+1}{3}$ and $\mathrm{fx}=\frac{2 x+1}{3}$, for all $\mathrm{x} \in \mathrm{X}$. Suppose that $\mathrm{f}$ and g satisfy property ( E. A. ) ,then there exists a sequence $\left\{\mathrm{x}_{\mathrm{n}}\right\}$ in X satisfying $\lim _{n \rightarrow \infty} \mathrm{fx}_{\mathrm{n}}=\lim _{n \rightarrow \infty} \mathrm{gx}_{\mathrm{n}}=\mathrm{z}$ for some $\mathrm{z} \in$ $X$. Therefore, $\lim _{n \rightarrow \infty} x_{n}=3 z-1$ and $\lim _{n \rightarrow \infty} x_{n}=\frac{3 z-1}{2}$. Thus, $z$ $=\frac{1}{3}$, which is a contradiction, since $\frac{1}{3}$ is not contained in $\mathrm{X}$. Hence $f$ and $g$ does not satisfy property (E. A. ) .

Example 1.9. Let $X=R^{+}$and $d$ be the usual metric on $X$..Also define $f, g: X \rightarrow X$ by

$\mathrm{fx}=0$, if $0<\mathrm{x} \leq 1$ and $\mathrm{fx}=1$, if $\mathrm{x}>1$ or $\mathrm{x}=0$; and $\mathrm{gx}=$ $[\mathrm{x}]$, the greatest integer that is less than or equal to $\mathrm{x}$, for all $\mathrm{x}$ $\in X$. Consider a sequence $\left\{x_{n}\right\}=\left\{1+\frac{1}{n}\right\} n \geq 2$ in $(1,2)$, then we have $\lim _{n \rightarrow \infty} \mathrm{fx}_{\mathrm{n}}=1=\lim _{n \rightarrow \infty} \mathrm{gx}_{\mathrm{n}}$. Similarly for the sequence $\left\{\mathrm{y}_{\mathrm{n}}\right\}=\left\{1-\frac{1}{n}\right\} \mathrm{n} \geq 2$ in $(0,1)$, we have $\lim _{n \rightarrow \infty} \mathrm{fy}_{\mathrm{n}}=0=\lim _{n \rightarrow \infty}$ $\mathrm{gy}_{\mathrm{n}}$. Thus the pair $(\mathrm{f}, \mathrm{g})$ satisfy property (E. A. ) .

However, $f$ and $g$ are not weakly compatible as as each $\mathrm{u}_{1} \in(0,1)$ and $\mathrm{u}_{2} \in(1,2)$ are coincidence points of $\mathrm{f}$ and $\mathrm{g}$, where they do not commute. Moreover, they commute at $\mathrm{x}=$ $0,1,2 \ldots$ but none of these points are coincidence points of $f$ and $\mathrm{g}$.

It was pointed out in [1] that property ( E. A.) buys containment of ranges without any continuity requirements besides minimizes the commutativity conditions of the maps to the commutativity at their points of coincidence. Moreover, property ( E. A.) Allows replacing the completeness requirement of the space with a more natural condition of closeness of the range. 
Definition 1.9. Let $A, B, S$ and $T$ be self-maps of a metric space $(\mathrm{X}, \mathrm{d})$ Two pairs $(\mathrm{A}, \mathrm{S})$ and $(\mathrm{B}, \mathrm{T})$ satisfy a common E.A. property if there exists a sequences $\left\{x_{n}\right\}$ and $\left\{y_{n}\right\}$ in $X$ such that $\lim _{\mathrm{n} \rightarrow \infty} A x_{n}=\lim _{n \rightarrow \infty} S x_{n} \lim _{n \rightarrow \infty} B y_{n}=\lim _{n \rightarrow \infty} T_{n}=z$ for some $\mathrm{z} \in \mathrm{X}$.

\section{MAIN RESULTS}

Theorem 2.1. Let $\mathrm{A}, \mathrm{B}, \mathrm{S}$ and $\mathrm{T}$ be self maps of a metric space $(\mathrm{X}, \mathrm{d})$ satisfying the following conditions:

$$
\mathrm{A}(\mathrm{X}) \subset \mathrm{T}(\mathrm{X}) \text { and } \mathrm{B}(\mathrm{X}) \subset \mathrm{S}(\mathrm{X}),
$$

$\mathrm{d}(\mathrm{Ax}, \mathrm{By}) \leq \phi\{\mathrm{d}(\mathrm{Sx}, \mathrm{Ty}), \mathrm{d}(\mathrm{Ax}, \mathrm{Sx}), \mathrm{d}(\mathrm{By}, \mathrm{Ty})$ $, \mathrm{d}(\mathrm{Sx}, \mathrm{By}), \mathrm{d}(\mathrm{Ax}, \mathrm{Ty})\}$ for all $\mathrm{x}, \mathrm{y}$ in $\mathrm{X}$, where $\varphi$ : $\left(\mathrm{R}^{+}\right)^{5} \rightarrow \mathrm{R}^{+}$is in the class $\mathrm{F}$ of all upper semicontinuous mappings, strictly non-decreasing in each coordinate variables . pairs $(\mathrm{A}, \mathrm{S})$ or $(\mathrm{B}, \mathrm{T})$ satisfy property ( E. A. ) , pairs $(\mathrm{A}, \mathrm{S})$ and $(\mathrm{B}, \mathrm{T})$ are weakly compatible.

If the range of one of $\mathrm{A}, \mathrm{B}, \mathrm{S}$ and $\mathrm{T}$ is a closed subset of $\mathrm{X}$, then $\mathrm{A}, \mathrm{B}, \mathrm{S}$ and $\mathrm{T}$ have a unique common fixed point in $\mathrm{X}$.

Proof. Suppose that $(B, T)$ satisfies the property ( E. A. ) . Then there exists a sequence $\left\{x_{n}\right\}$ in $X$ such that $\lim _{n \rightarrow \infty} B x_{n}=$ $\lim _{\mathrm{n} \rightarrow \infty} \operatorname{Tx}_{\mathrm{n}}=\mathrm{z}$ for some $\mathrm{z} \in \mathrm{X}$.

Since $B(X) \subset S(X)$, therefore, there exists a sequence $\left\{y_{n}\right\} \in$ $X$ such that $\lim _{n \rightarrow \infty} B x_{n}=\lim _{n \rightarrow \infty} S y_{n}=z$.

Now we shall show that $\lim _{n \rightarrow \infty} A y_{n}=z$. We claim that $\lim _{n \rightarrow \infty} \operatorname{Ay}_{\mathrm{n}}=l$.

From (2.2), we hav

$d\left(A y_{n}, B x_{n}\right) \leq \phi\left\{d\left(S_{n}, T x_{n}\right), d\left(A y_{n}, S y_{n}\right), d\left(B x_{n}, T_{n}\right)\right.$, $\mathrm{d}\left(\mathrm{Sy}_{\mathrm{n}}, \mathrm{Bx}_{\mathrm{n}}\right)$

$$
\left.\mathrm{d}\left(\mathrm{Ay}_{\mathrm{n}}, \mathrm{Tx}_{\mathrm{n}}\right)\right\}
$$

Proceeding limit as $\mathrm{n} \rightarrow \infty$

$$
\begin{aligned}
\mathrm{d}(l, \mathrm{z}) & \leq \phi\{\mathrm{d}(\mathrm{z}, \mathrm{z}), \mathrm{d}(l, \mathrm{z}), \mathrm{d}(\mathrm{z}, \mathrm{z}), \mathrm{d}(\mathrm{z}, \mathrm{z}), \mathrm{d}(l, \mathrm{z})\} \\
& =\phi\{0, \mathrm{~d}(l, \mathrm{z}), 0,0, \mathrm{~d}(l, \mathrm{z})\} \leq \varphi(\mathrm{t}, \mathrm{t}, \mathrm{t}, \mathrm{t}, \mathrm{t})<\mathrm{t}, \text { where }
\end{aligned}
$$$$
\mathrm{t}=\mathrm{d}(l, \mathrm{z}), \quad \text { we have } l=\mathrm{z}
$$

Therefore, $\lim _{\mathrm{n} \rightarrow \infty} \mathrm{Ay}_{\mathrm{n}}=\mathrm{z}$.

Suppose that $S(X)$ is a closed subset of $X$. Then $z=S u$ for some $u \in X$. Subsequently, we have $\lim _{n \rightarrow \infty} A y_{n}=\lim _{n \rightarrow \infty} B x_{n}$ $=\lim _{\mathrm{n} \rightarrow \infty} \mathrm{Tx}_{\mathrm{n}}=\lim _{\mathrm{n} \rightarrow \infty} \mathrm{Sy}_{\mathrm{n}}=\mathrm{z}=\mathrm{Su}$.

From (2.2) we have

$\mathrm{d}\left(\mathrm{Au}, \mathrm{Bx}_{\mathrm{n}},\right) \leq \phi\left\{\mathrm{d}\left(\mathrm{Su}, \mathrm{Tx}_{\mathrm{n}}\right), \mathrm{d}(\mathrm{Au}, \mathrm{Su}), \mathrm{d}\left(\mathrm{Bx}_{\mathrm{n}}, \mathrm{Tx}_{\mathrm{n}}\right)\right.$, $\mathrm{d}\left(\mathrm{Su}, \mathrm{Bx}_{\mathrm{n}}\right)$,

$$
\left.\mathrm{d}\left(\mathrm{Au}, \mathrm{Tx}_{\mathrm{n}}\right)\right\} .
$$

Letting limit as $\mathrm{n} \rightarrow \infty$, we have $\mathrm{Au}=\mathrm{Su}=\mathrm{z}$.

Since $\mathrm{A}(\mathrm{X}) \subset \mathrm{T}(\mathrm{X})$, so there exists $\mathrm{v} \in \mathrm{X}$ such that $\mathrm{z}=\mathrm{Au}=$ Tv.

Now, we claim that $\mathrm{z}=\mathrm{Tv}=\mathrm{Bv}$.

From (2.2) ),

$\mathrm{d}(\mathrm{Au}, \mathrm{Bv}) \leq \phi\{\mathrm{d}(\mathrm{Su}, \mathrm{Tv}), \mathrm{d}(\mathrm{Au}, \mathrm{Su}), \mathrm{d}(\mathrm{Bv}, \mathrm{Tv}),, \mathrm{d}(\mathrm{Su}, \mathrm{Bv})$, $\mathrm{d}(\mathrm{Au}, \mathrm{Tv})\}$, we have

$\mathrm{z}=\mathrm{Bv}$.
Thus we have $\mathrm{Au}=\mathrm{Su}=\mathrm{Tv}=\mathrm{Bv}=\mathrm{z}$.

Since the pair (A, S ) is weak compatible which implies ASu $=\mathrm{SAu}$ i.e, $\mathrm{Az}=\mathrm{Sz}$.

From (2.2)

$\mathrm{d}(\mathrm{Az}, \mathrm{Bv}) \leq \phi\{\mathrm{d}(\mathrm{Sz}, \mathrm{Tv}), \mathrm{d}(\mathrm{Az}, \mathrm{Sz}),, \mathrm{d}(\mathrm{Bv}, \mathrm{Tv}), \mathrm{d}(\mathrm{Sz}, \mathrm{Bv})$, $\mathrm{d}(\mathrm{Az}, \mathrm{Tv})\}$,imply that $\mathrm{Az}=\mathrm{Sz}=\mathrm{z}$.

The weak compatibility of $\mathrm{B}$ and $\mathrm{T}$ implies that $\mathrm{BTV}=\mathrm{TBv}$ ,i.e., $\mathrm{Bz}=\mathrm{Tz}$.

Now we shall show that $\mathrm{z}$ is the common fixed point of $\mathrm{B}$.

From (2.2), one obtains $\mathrm{Bz}=\mathrm{z}$,

Hence $\mathrm{Az}=\mathrm{Bz}=\mathrm{Sz}=\mathrm{Tz}=\mathrm{z}$ and $\mathrm{z}$ is a common fixed point of $\mathrm{A}$, $\mathrm{B}, \mathrm{S}$ and $\mathrm{T}$.

Example 2.1. Let $X=[0,2]$ equipped with the Euclidian distance .Define A,B,S and T by

$$
\begin{aligned}
& A x=T x=\left\{\begin{array}{l}
0 \text { if } 0 \leq x<1 \\
1 \text { if } 1 \leq x \leq 2
\end{array}\right. \\
& B x=S x= \begin{cases}0 \text { if } 0 \leq x<1 \\
2 \text { if } 1 \leq x \leq 2\end{cases}
\end{aligned}
$$

The mapping $\phi:(\mathrm{R}+)^{5} \rightarrow \mathrm{R}^{+}$defined by $\phi\left(\mathrm{x}_{1}, \mathrm{x}_{2}, \mathrm{x}_{3}, \mathrm{x}_{4}, \mathrm{x}_{5}\right)=\mathrm{x}_{1}$ Then

$\mathrm{d}(\mathrm{Sx}, \mathrm{Ty})$ $\leq$ $\phi\{d(\mathrm{Sx}, \mathrm{Ty}), \mathrm{d}(\mathrm{Ax}, \mathrm{Sx}), \mathrm{d}(\mathrm{By}, \mathrm{Ty}), \mathrm{d}(\mathrm{Ax}, \mathrm{Ty}), \mathrm{d}(\mathrm{By}, \mathrm{Sx})\} \quad$ for all $\mathrm{x}, \mathrm{y} \& \mathrm{X}$ and consider $x_{n}=\frac{1}{n} \quad . \operatorname{Lim}_{\mathrm{n} \rightarrow \infty} \mathrm{Ax}_{\mathrm{n}}=\lim _{\mathrm{n} \rightarrow \infty} \mathrm{Bx}_{\mathrm{n}}=$ $\lim _{\mathrm{n} \rightarrow \infty} \operatorname{Tx}_{\mathrm{n}}=\lim _{\mathrm{n} \rightarrow \infty} \mathrm{Sx_{ \textrm {n } }}=0$.

Hence pairs $(\mathrm{A}, \mathrm{S})$ and $(\mathrm{B}, \mathrm{T})$ satisfy E.A. property .

Also $A(X)=T(X)=\{0,1\}$ and $B(X)=S(X)=\{0,2\}$ are a closed subset of $\mathrm{X}$. Moreover, pairs $(\mathrm{A}, \mathrm{S})$ and $(\mathrm{B}, \mathrm{T})$ are weakly compatible. Thus all the conditions of the above theorem are satisfied . 0 is the unique common fixed point of $\mathrm{A}, \mathrm{B}, \mathrm{S}$ and $\mathrm{T}$.

In 2008, Kubiaczyk Sharma[6] proved the following fixed theorem.

Corollary 2.1. Let $A, B, S$ and $T$ be self maps of a metric space $(X, d)$ satisfying $(2.1),(2.3),(2.4)$ and the following:

(2.5) $\mathrm{d}(\mathrm{Ax}, \mathrm{By}) \leq \mathrm{k} \max \{\mathrm{d}(\mathrm{Sx}, \mathrm{Ty}), \mathrm{d}(\mathrm{Ax}, \mathrm{Sx}), \mathrm{d}(\mathrm{By}, \mathrm{Ty})$ $, \mathrm{d}(\mathrm{Sx}, \mathrm{By}), \mathrm{d}(\mathrm{Ax}, \mathrm{Ty})\}$ for all $\mathrm{x}, \mathrm{y}$ in $\mathrm{X}$, where $\mathrm{k} \varepsilon$ $(0,1)$.

If the range of one of $\mathrm{A}, \mathrm{B}, \mathrm{S}$ and $\mathrm{T}$ is a closed subset of $\mathrm{X}$, then $\mathrm{A}, \mathrm{B}, \mathrm{S}$ and $\mathrm{T}$ have a unique common fixed point in $\mathrm{X}$.

Proof . Take in the above Theorem $\phi\left(\mathrm{x}_{1}, \mathrm{x}_{2}, \mathrm{x}_{3}, \mathrm{x}_{4}, \mathrm{x}_{5}\right)=\max$ $\left\{\mathrm{x}_{1}, \mathrm{x}_{2}, \mathrm{x}_{3}, \mathrm{x}_{4}, \mathrm{x}_{5}\right\}$

Example 2.2. Let $X=[0,2]$ equipped with the Euclidian distance Define the self maps A,B,S and T:X $\rightarrow \mathrm{X}$ by 


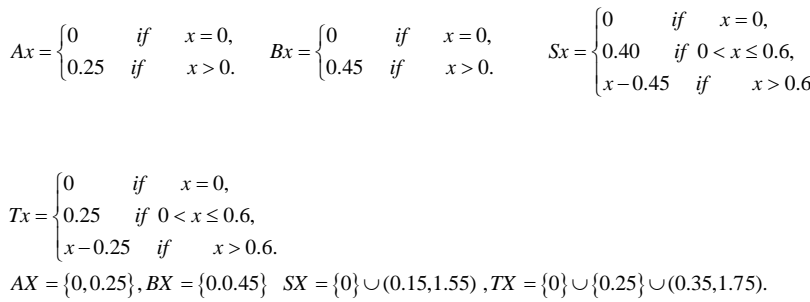

Let us consider the sequence $\mathrm{x}_{\mathrm{n}}=0.60+1 / \mathrm{n}$, then $\mathrm{Ax}_{\mathrm{n}} \rightarrow 0.25$, $\mathrm{Bx}_{\mathrm{n}} \rightarrow 0.45 \mathrm{Cx}_{\mathrm{n}} \rightarrow 0.15, \mathrm{Tx}_{\mathrm{n}} \rightarrow 0.35, \mathrm{ASx}_{\mathrm{n}} \rightarrow 0.25, \mathrm{SAx}_{\mathrm{n}} \rightarrow 0.40$, $\mathrm{BTx}_{\mathrm{n}} \rightarrow 0.45, \mathrm{Bx}_{\mathrm{n}} \rightarrow 0.25$.Pairs $(\mathrm{A}, \mathrm{S})$ and $(\mathrm{B}, \mathrm{T})$ are non compatible. If we take $\mathrm{k}=0.6$, and $\mathrm{t}=1$, then $\mathrm{A}, \mathrm{B}, \mathrm{S}$ and $\mathrm{T}$ satisfy all the conditions of the theorem and 0 is the unique common fixed point of A,B,S and T. Moreover, A,B,S and T are discontinuous at the fixed point 0 .

Next we consider a function $\psi: \mathrm{R}^{+} \rightarrow \mathrm{R}^{+}$satisfying the conditions

$(*)\left\{\begin{array}{l}\psi \text { is continuous and nondecreasing on } \mathrm{R}^{+} \\ \psi(\mathrm{t})<\mathrm{t} \text { for all } \mathrm{t}>0 .\end{array}\right.$,

We note that $\psi(1)=1$ and $\psi(t)<t$ for all $t>0$.

$\psi(\mathrm{d}(\mathrm{x}, \mathrm{y}))<\mathrm{d}(\mathrm{x}, \mathrm{y})$ holds for all $\mathrm{x}, \mathrm{y}$ in $\mathrm{X}$.

Theorem 2.3. Let A,B,S and $\mathrm{T}$ be self maps of a metric space $(\mathrm{X}, \mathrm{d})$ satisfying $(2.1),(2.3),(2.4)$ and the following:

$$
\begin{aligned}
& \mathrm{d}(\mathrm{Ax}, \mathrm{By}) \leq \psi(\max \{\mathrm{d}(\mathrm{Sx}, \mathrm{Ty}), \mathrm{d}(\mathrm{Ax}, \mathrm{Sx}), \\
& \mathrm{d}(\mathrm{By}, \mathrm{Ty}), \mathrm{d}(\mathrm{Sx}, \mathrm{By}), \mathrm{d}(\mathrm{Ax}, \mathrm{Ty})\} \text { for all } \mathrm{x}, \mathrm{y} \text { in } \mathrm{X} .
\end{aligned}
$$

If the range of one of $\mathrm{A}, \mathrm{B}, \mathrm{S}$ and $\mathrm{T}$ is a closed subset of $\mathrm{X}$, then $\mathrm{A}, \mathrm{B}, \mathrm{S}$ and $\mathrm{T}$ have a unique common fixed point in $\mathrm{X}$.

Proof. Suppose that $(B, T)$ satisfies the E.A property. Then there exists a sequence $\left\{x_{n}\right\}$ in $X$ such that $\lim _{n \rightarrow \infty} B x_{n}=$ $\lim _{\mathrm{n} \rightarrow \infty} \mathrm{Tx}_{\mathrm{n}}=\mathrm{z}$ for some $\mathrm{z} \in \mathrm{X}$.

Since $B X \subset S X$ there exists a sequence $\left\{y_{n}\right\} \in X$ such that $\mathrm{Bx}_{\mathrm{n}}=\mathrm{Sy}_{\mathrm{n}}=\mathrm{z}$. Hence $\lim _{\mathrm{n} \rightarrow \infty} \mathrm{Sy}_{\mathrm{n}}=\mathrm{z}$.

We shall show that $\lim _{n \rightarrow \infty} A_{n}=z$.

From (2.6) we have

$d\left(A y_{n}, B x_{n}\right) \leq \psi\left(\max \left\{d\left(S y_{n}, T x_{n}\right), d\left(A y_{n}, S y_{n}\right), d\left(B x_{n}\right.\right.\right.$ , $\left.\mathrm{Tx}_{\mathrm{n}}\right), \mathrm{d}\left(\mathrm{Sy}_{\mathrm{n}}, \mathrm{Bx}_{\mathrm{n}}\right)$,

$$
\left.\left.\mathrm{d}\left(\mathrm{Ay}_{\mathrm{n}}, \mathrm{Tx}_{\mathrm{n}}\right)\right\}\right)
$$

Proceeding limit as $\mathrm{n} \rightarrow \infty$, one obtain, $\lim _{\mathrm{n} \rightarrow \infty} \mathrm{Ay}_{\mathrm{n}}=\mathrm{z}$.

Suppose that $S(X)$ is a closed subspace of $X$. Then $z=S u$ for some $\mathrm{u} \in \mathrm{X}$. Subsequently we have

$\lim _{\mathrm{n} \rightarrow \infty} \mathrm{Ay}_{\mathrm{n}}=\lim _{\mathrm{n} \rightarrow \infty} \mathrm{Bx}_{\mathrm{n}}=\lim _{\mathrm{n} \rightarrow \infty} \mathrm{Tx}_{\mathrm{n}}=\lim _{\mathrm{n} \rightarrow \infty} \mathrm{Sy}_{\mathrm{n}}=\mathrm{z}=\mathrm{Su}$.

Now, we shall show that $\mathrm{Au}=\mathrm{Su}$. From (2.6) we have

$\mathrm{d}\left(\mathrm{Au}, \mathrm{Bx}_{\mathrm{n}}\right) \leq \psi\left(\max \left\{\mathrm{d}\left(\mathrm{Su}, \mathrm{Tx}_{\mathrm{n}}\right), \mathrm{d}(\mathrm{Au}, \mathrm{Su}), \mathrm{d}\left(\mathrm{Bx}_{\mathrm{n}}, \mathrm{Tx}_{\mathrm{n}}\right)\right.\right.$, $\mathrm{d}\left(\mathrm{Su}, \mathrm{Bx}_{\mathrm{n}}\right)$,

$$
\left.\mathrm{d}\left(\mathrm{Au}, \mathrm{Tx}_{\mathrm{n}}\right)\right\}
$$

Letting limit as $n \rightarrow \infty$, we get

$\mathrm{d}(\mathrm{Au}, \mathrm{zt}) \leq \psi(\max \{\mathrm{d}(\mathrm{z}, \mathrm{z}), \mathrm{d}(\mathrm{Au}, \mathrm{z}), \mathrm{d}(\mathrm{z}, \mathrm{z}), \mathrm{d}(\mathrm{z}, \mathrm{z})$,

$$
\mathrm{d}(\mathrm{Au}, \mathrm{z})\}) \text {, using }(*) \text {, we have }, \mathrm{Au}=\mathrm{Su}=\mathrm{z} \text {. }
$$

Since $A X \subset T X$, so there exists $v \in X$ such that $z=A u=T v$. Now, we claim that $\mathrm{z}=\mathrm{Tv}=\mathrm{Bv}$.

From (2.6) we have

$\mathrm{d}(\mathrm{Au}, \mathrm{Bv}) \leq \psi(\max \{\mathrm{d}(\mathrm{Su}, \mathrm{Tv}), \mathrm{d}(\mathrm{Au}, \mathrm{Su}), \mathrm{d}(\mathrm{Bv}, \mathrm{Tv})$, $\mathrm{d}(\mathrm{Su}, \mathrm{Bv})$,

$\mathrm{d}(\mathrm{Au}, \mathrm{Tv})\})$,

, using (*), we have, $\mathrm{z}=\mathrm{Bv}$. Thus we have $\mathrm{Au}=\mathrm{Su}=\mathrm{Tv}=$ $\mathrm{Bv}=\mathrm{z}$.

Since the pair $(\mathrm{A}, \mathrm{S})$ is weak compatible which implies $\mathrm{ASu}$ $=\mathrm{SAu}$ i.e, $\mathrm{Az}=\mathrm{Sz}$

From (2.6),

$\mathrm{d}(\mathrm{Az}, \mathrm{Bv},) \leq \psi(\max \{\mathrm{d}(\mathrm{Sz}, \mathrm{Tv}), \mathrm{Fd}(\mathrm{Az}, \mathrm{Sz}), \mathrm{d}(\mathrm{Bv}, \mathrm{Tv})$, $\mathrm{d}(\mathrm{Sz}, \mathrm{Bv})$,

$\mathrm{d}(\mathrm{Az}, \mathrm{Tv})\})$ using $(*)$, we have, $\mathrm{Az}=\mathrm{Sz}=\mathrm{z}$.

The weak compatibility of $\mathrm{B}$ and $\mathrm{T}$ implies that $\mathrm{BTv}=\mathrm{TBv}$ ,i.e., $\mathrm{Bz}=\mathrm{Tz}$.

Now we shall show that $\mathrm{z}$ is the common fixed point of A, B, $\mathrm{T}$ and $\mathrm{S}$.

Suppose that $\mathrm{Bz} \neq \mathrm{z}$. Then using (2.6) one obtain $\mathrm{Bz}=\mathrm{z}$.

Hence $\mathrm{Az}=\mathrm{Bz}=\mathrm{Sz}=\mathrm{Tz}=\mathrm{z}$ and $\mathrm{z}$ is a common fixed point of $\mathrm{A}, \mathrm{B}, \mathrm{S}$ and $\mathrm{T}$.

Uniqueness follows easily.

Theorem 2.4. Let $A, B, S$ and $T$ be self maps of a metric space (X,d) satisfying (2.1),(2.4) and the following conditions:

(2.7) pairs $(\mathrm{A}, \mathrm{S})$ and $(\mathrm{B}, \mathrm{T})$ satisfy a common E.A. property

If the range of $\mathrm{S}$ and $\mathrm{T}$ is a closed subset of $\mathrm{X}$, then $\mathrm{A}, \mathrm{B}, \mathrm{S}$ and $\mathrm{T}$ have a unique common fixed point in $\mathrm{X}$.

Proof. Suppose that (A,S ) and (B, T) satisfy a common E.A. property. Then there exists a sequences $\left\{x_{n}\right\}$ and $\left\{y_{n}\right\}$ in $X$ such that

$\lim _{n \rightarrow \infty} \mathrm{Ax}_{\mathrm{n}}=\lim _{\mathrm{n} \rightarrow \infty} \mathrm{Sx}_{\mathrm{n}} \lim _{\mathrm{n} \rightarrow \infty} \mathrm{By}_{\mathrm{n}}=\lim _{\mathrm{n} \rightarrow \infty} \mathrm{Ty}_{\mathrm{n}}=\mathrm{z}$ for some $z \in X$.

Since $S(X)$ and $T(X)$ are closed subsets of $X$, we obtain $\mathrm{z}=\mathrm{Su}=\mathrm{T} v$ for some $\mathrm{u}, \mathrm{v}$ in $\mathrm{X}$.

From (2.6),

$\mathrm{d}\left(\mathrm{Au}, \mathrm{By}_{\mathrm{n}}\right) \leq \psi \max \left\{\mathrm{d}\left(\mathrm{Su}, \mathrm{Ty}_{\mathrm{n}}\right), \mathrm{d}(\mathrm{Au}, \mathrm{Su}), \mathrm{d}\left(\mathrm{By}_{\mathrm{n}}, \mathrm{Ty}_{\mathrm{n}},\right)\right.$, $\mathrm{d}\left(\mathrm{Su}, \mathrm{By} \mathrm{n}_{\mathrm{n}}\right)$,

$$
\left.\left.\mathrm{d}\left(\mathrm{Au}, \mathrm{Ty}_{\mathrm{n}}\right)\right\}\right)
$$

Letting $\mathrm{n} \rightarrow \infty$ and using $(*)$, we have, $\mathrm{z}=\mathrm{Au}=\mathrm{Su}=\mathrm{Tv}$.

The rest of the proof follows from the above theorem. 


\section{REFERENCES}

[1] M.Aamri and D.EI .Moutawakil, Some new common fixed point theorems under strict contractive conditions , J. Math. Anal. Appl. 270(2002), 181-188.

[2] S.Banach, Surles operations dans les ensembles abstraits et leur application aux equationsitegrales, Fund.Math.(1922), 3, 133- 181

[3] R. Chugh and S. Kumar, Common fixed points for weakly compatible maps, Proc. Indian Acad. Sci. (Math. Sci.), Vol. 111, No.2(2001), 241- 247.

[4] R. Chugh and S. Kumar, Common fixed point theorem using minimal commutativity and reciprocal conditions in metric space, Scientiac Mathematiace Japonica, 56 No.2 (2002), 269-275.

[5] G,Jungck, Commuting mappings and fixed point, Amer. Math. Monthly 83 (1976), 261-263.

[6] G.Jungck, Compatible mappings and common fixed points, Int. J. Math. Math. Sci 9(1986), 771-779.

[7] G.Jungck and B.E. Rhoades,Fixed point for set valued functions without continuity, Indian J. Pure Appl. Math., 29(3) (1998), 227-238.
[8] G. Jungck, P.P.Murthy, Y.J.Cho, Compatible mappings of type(A) and Common fixed points, Math. Japonica, 38(1993), 381-390.

[9] M. Imdad Javid Ali , Jungck's common fixed point theorem and E.A property, Acta Mathematica Sinica, an., 2008, Vol. 24, No. 1, pp. 87-94.

[10] R Kannan, Some Results on fixed points, Bull. Cal. Math. Soc., 60, (1968) 71-76.

[11] H.K .Pathak, Y.J.Cho, S.M.Kang, Remarks on R-Weakly commuting Mappings and common fixed point theorems, Bull. Korean Math. Soc.34 (1997),No.2, pp. 247-257.

[12] R. P.Pant, Common fixed points of non commuting mappings, J. Math. Anal. Appl. 188(1994), 436-440.

[13] R. P.Pant, Common fixed points theorems for contractive maps, J. Math. Anal. Appl. 226(1998), 251-258.

[14] W. F. Pfeffer, More on involutions of a circle, Amer. Math. Monthly, 81 (1974), 613-616.

[15] S. Sessa, On a weak commutativity conditions of mappings in fixed point consideration, Publ. Inst. Math. Beograd, 32(46) (1982), 146-153. 